Pacific Journal of Mathematics

AN ABSTRACT DISINTEGRATION THEOREM 


\section{AN ABSTRACT DISINTEGRATION THEOREM}

\section{BenNo Fuchssteiner}

\section{A Strassen-type disintegration theorem for convex cones with localized order structure is proved. As an example a flow theorem for infinite networks is given.}

Introduction. It has been observed by several authors (e.g., $|\mathbf{9}|,|\mathbf{1 0}|,|\mathbf{1 3}|$ and $|\mathbf{1 4}|)$ that the essential part of the celebrated Strassen disintegration theorem $(|12|$ or $|7|)$ consists of a rather sophisticated Hahn-Banach argument combined with a measure theoretic argument like the Radon Nikodym theorem. For this we refer especially to a theorem given by M. Valadier $|13|$ and also by M. Neumann $|10|$. We first extend this result (in the formulation of $|\mathbf{1 0}|)$ to convex cones. This extension is nontrivial because in the situation of convex cones one looses in general the required measure theoretic convergence properties if a linear functional is decomposed with respect to an integral over sublinear functionals. For avoiding these difficulties we have to combine a maximalityargument with, what we call, a localized order structure. On the first view this order structure looks somewhat artificial, but it certainly has some interest in its own since it turns out that the disintegration is compatible with this order structure. The usefulness of these order theoretic arguments is illustrated by giving as an example a generalization of Gale's [4] celebrated theorem on flows in networks (see also Ryser [11]).

1. A Disintegration theorem. Let $(\Omega, \Sigma, m)$ be a measure space with $\sigma$-algebra $\Sigma$ and positive $\sigma$-finite measure $m$. By $L_{*}^{1}(m)$ we denote the convex cone of $\boldsymbol{R}_{*}$-valued $\left(\boldsymbol{R}_{*}=\boldsymbol{R} \cup\{-\infty\}\right)$ measurable functions on $\Omega$ such that their positive part (but not necessarily the negative part) is integrable with respect to $m$. Of course, two elements of $L_{*}^{1}(m)$ are considered to be equal if they coincide almost everywhere. Note, that for every $f \in L_{*}^{1}(m)$ the integral $\int_{\Omega} f d m$ exists in $\boldsymbol{R}_{*}$, and that the function $-\infty$ is an element of $L_{*}^{1}(m)$.

Throughout the paper we assume $0 \cdot(-\infty)=0$. We are interested in operators $p: F \rightarrow L_{*}^{1}(m)$, where $F$ is some convex cone. As usual, such an operator is said to be sublinear if it is positively homogeneous (i.e., $P(\lambda x)=\lambda P(x) \forall x \in F, \forall \lambda \geqq 0$ ) and subadditive. If it is superadditive instead of subadditive then it is called superlinear. A linear operator is one which is both sublinear and superlinear.

For the study of operators $F \rightarrow L_{*}^{1}$ we introduce in $F$ an order structure $\leqq_{\omega, \omega \in \Omega}$ which is localized on $\Omega$. This means that for every 
$\omega \in \Omega$ we have given an preorder $\leqq_{\omega}$ on $F$ (a reflexive and transitive relation on $F$ ) which is compatible with the cone structure of $F$ (see [2] or [3]).

An operator $p: F \rightarrow L_{*}^{1}(m)$ is said to be monotone with respect to this localized order structure ( $\Omega$-monotone for short) if for $x, y \in$ $F$ we always have:

$$
P(x) \leqq P(y) m \text {-almost everywhere on }\left\{\omega \in \Omega \mid x \leqq{ }_{\omega} y\right\} .
$$

Disintegration Theorem 1. Let $\mu: F \rightarrow \boldsymbol{R}_{*}$ be linear and let $P: F \rightarrow L_{*}^{1}(m)$ be an $\Omega$-monotone sublinear operator with

$$
\mu(x) \leqq \int_{\Omega} P(x) d m \text { for all } x \in F .
$$

Then there is an $\Omega$-monotone linear operator $T: F \rightarrow L_{*}^{1}(m)$ with $T \leqq P$ (i.e., $T(x) \leqq P(x) \forall x \in F)$ such that

$$
\mu(x) \leqq \int_{\Omega} T(x) d m \text { for all } x \in F
$$

Proof. Let $\Phi$ be the convex cone consisting of all simple $\Sigma$-measurable functions $\phi: \Omega \rightarrow F$. Here, a function $\phi$ is called simple if $\phi(\Omega)$ is a finite set and if, for every $x \in F$, the set $\{\omega \in \Omega \mid \phi(\omega)=x\}$ belongs to $\Sigma$. In $\Phi$ we consider the preorder given by:

$$
\phi_{1} \leqq \phi_{2} \Longleftarrow \phi_{1}(\omega) \leqq{ }_{\omega} \phi_{2}(\omega) \text { for } m \text {-almost all } \omega \in \Omega \text {. }
$$

Then

$$
p(\phi)=\int_{\Omega} P(\phi(\omega))(\omega) d m(\omega)
$$

defines a monotone sublinear functional on $\Phi$. And

$$
\delta(\phi)=\left\{\begin{array}{l}
\mu(x) \text { if } \phi \text { is constant (with value } x \text { ) on } \Omega \\
-\infty \text { otherwise }
\end{array}\right.
$$

gives us a superlinear functional on $\Phi$, with $\delta \leqq p$. According to the sandwich theorem ([2] or [3]) there is a monotone linear $\nu$ with $\delta \leqq \nu \leqq p$. And by using Zorn's lemma we can further assume that $\nu$ is maximal among the linear functionals $\leqq p$. Now, for $A \in \Sigma$ and $x \in F$, we define

$$
d(A, x)=\nu\left(1_{A} x\right),
$$

where $1_{A}$ is the characteristic function of $A$, i.e., $1_{A}(\omega)=\{1$ if $\omega \in$ $A, 0$ otherwise $\}$. We claim that for $x, y \in F$ and $A \in \Sigma$ the following 
are true:

$$
d(A, \cdot) \text { is linear on } F
$$$$
d(\cdot, x) \text { is an additive set function on } \Sigma
$$

(8) when $x \leqq{ }_{\omega} y$ for $m$-almost all $\omega \in A$ then $d(A, x) \leqq d(A, y)$

(9) if $A_{n}$ is a sequence of pairwise disjoint sets in $\Sigma$ then

$$
d\left(\bigcup_{n \in N} A_{n}, x\right)=\lim _{m \rightarrow \infty} \operatorname{lnf}_{n=1}^{m} d\left(A_{n}, x\right) .
$$

The assertions (4)-(9) prove the theorem in the following way:

(5) and (9) show clearly that $d(\cdot, x)$ is a signed measure on $\Omega$. Assertion (8) implies that this measure is absolutely continuous with respect to $m$. This is so, because from $m(A)=0$ we obviously get $x \leqq \leqq_{\omega} 0$ and $0 \leqq{ }_{\omega} x$ for almost all $\omega \in A$, and hence $d(A, x)=$ $d(A, 0)=0$.

Now, we apply the Radon-Nikodym theorem to find a measurable function $T(x)$ such that

$$
d(A, x)=\int_{A} T(x) d m .
$$

Then, because of (7), the positive part of $T(x)$ is absolutely integrable with respect to $m$, so $T(x)$ must belong to $L_{*}^{1}(m)$. Assertion (4) gives that $x \rightarrow T(x)$ is linear, and from (6) and (7) we obtain (2) and $T(x) \leqq P(x)$. Finally, we show that $x \rightarrow T(x)$ is in fact $\Omega$ monotone. Consider $x, y \in F$, put $B=\left\{\omega \in \Omega \mid x \leqq_{\omega} y\right\}$ and assume $T(x)(\omega)>T(y)(\omega)$ for $\omega \in A \subset B$ with $m(A)>0$. Then, without loss of generality, we may further assume that $\int_{A} T(x) d m>-\infty$ (otherwise we replace $A$ by a suitable subset). And we have in contradiction to $(8)$

$$
d(A, x)=\int_{A} T(x) d m>\int_{A} T(y) d m=d(A, y) .
$$

So we are left with:

Proof of (4)-(9): (4) and (5) are easy consequences of the linearity of $\nu$, and (6) and (7) follow immediately from $\delta \leqq \nu \leqq p$. Let $x \leqq{ }_{\omega} y$ for $m$-almost all $\omega \in A$. Then $1_{A} \cdot x \leqq 1_{A} \cdot y$ and by monotony of $\nu$ we get: 


$$
d(A, x)=\nu\left(1_{A} \cdot x\right) \leqq \nu\left(1_{A} \cdot y\right)=d(A, y) .
$$

So we have also proved (8).

The proof of (9) is a little bit more complicated and depends essentially on the maximality of $\nu$. So, let the $A_{n}$ be as in (9) and define for arbitary $\phi \in \Phi$ :

$$
\rho(\phi)=\nu\left(1_{Y} \cdot \phi\right)+\liminf _{m \rightarrow \infty} \sum_{n=1}^{m} \nu\left(1_{A_{n}} \cdot \dot{\phi}\right),
$$

where $\gamma=\Omega \backslash \bigcup_{n \in N} A_{n}$. Then $\rho$ is superlinear (because of the inf in the $\lim$ inf). From $\nu \leqq p$ we get

$$
\rho(\phi) \leqq \nu\left(1_{Y} \cdot \phi\right)+\sum_{n=1}^{\infty} \int_{A_{n}} P(\phi(\omega))(\omega) d m(\omega)=\int_{\Omega} P(\phi(\omega))(\omega) d m=p(\phi) .
$$

Hence $\rho \leqq p$. The $\sigma$-additivity of $m$ implies $\rho \geqq \nu$ : To see this we use the following obvious inequality:

$$
\rho(\dot{\phi})+\limsup _{m \rightarrow \infty} \nu\left(1_{z_{m}} \cdot \dot{\phi}\right) \geqq \nu(\dot{\phi}),
$$

where $Z_{m}=\Omega \backslash\left(Y \cup \bigcup_{n=1}^{m} A_{n}\right)$. Since the $Z_{m}$ are decreasing to $\varnothing$ we get:

$$
\begin{aligned}
\limsup \nu\left(1_{Z_{m}} \cdot \phi\right) & \leqq \limsup _{m \rightarrow \infty} p\left(1_{z_{m}} \cdot \phi\right) \\
& \leqq \limsup _{m \rightarrow \infty} \int_{z_{m}} P(\phi(\omega))(\omega) d m(\omega) \leqq 0 .
\end{aligned}
$$

This inserted in (12) leads in fact to $\rho \geqq \nu$. Now, we apply the sandwich theorem to obtain a monotone linear $\bar{\nu}$ with $\rho \leqq \bar{\nu} \leqq \pi$. Then, because of $\rho \geqq \nu$ and the fact that $\nu$ was already maximal, this yields $\nu=\bar{\nu}$. Hence $\rho=\nu$. Inserting this in (11) and putting $\phi=1_{U^{\prime} \in N^{A} A_{n}} \cdot x$ we get the desired result.

REMARK 2. Without loss of generality one can assume the $\mu$ in Theorem 1 to be superlinear instead of linear, since the sandwich theorem applied to $\mu \leqq \int_{\Omega} P(\cdot) d m$ yields a linear $\bar{\mu}$ fulfilling the same inequality as $\mu$. Then application of Theorem 1 to $\bar{\mu}$ gives the desired result.

REMARK 3. A similar disintegration result can be obtained for linear functionals attaining values in a Dedekind complete Riesz space. This can be done by replacing the use of the sandwich theorem by the vector valued sandwich theorem of [3]. Of course, in this case the arguments depending on the Radon-Nikodym theorem do not work, and therefore the disintegration theorem for this situation has to be stated in a less elegant form. 
2. An Example. We consider a signed measure $\tilde{\mu}$ on some measurable space $(\widetilde{\Omega}, \Sigma)$ and a positive finite measure $\tau$ on $\Omega=\widetilde{\Omega} \times$ $\widetilde{\Omega}$. We recall that a bimeasure (see $|6|$ or $|8|$ ) on $\Omega$ is a function $\nu: \Sigma \times \Sigma \rightarrow \boldsymbol{R}$ being separately in each variable a signed measure. By $F$ we denote the convex cone of positive simple measurable functions on $\widetilde{\Omega}$, i.e., functions of the form $x=\sum_{n=1}^{N} \alpha_{n} 1_{A_{n}}$, where $\alpha_{n} \geqq 0, A_{n} \in \Sigma$. To every $x \in F$ we assign a function $\hat{x}: \Omega \rightarrow R$ by

$$
\hat{x}\left(\omega_{1}, \omega_{2}\right)=\max \left(x\left(\omega_{1}\right)-x\left(\omega_{2}\right), 0\right), \omega_{1}, \omega_{2} \in \widetilde{\Omega} .
$$

The map $x \rightarrow \widehat{x}$ is sublinear and a simple calculation shows that

$$
\tilde{\mu}(A) \leqq \tau(A \times \complement A) \text { for all } A \in \Sigma
$$

is equivalent to

$$
\int_{\Omega} x d \tilde{\mu} \leqq \int_{\Omega} \hat{x} d \tau \text { for all } x \in F .
$$

Using this and the disintegration theorem we get

FLOW THEOREM. The following are equivalent:

(i ) $\tilde{\mu}(A) \leqq \tau(A \times \complement A)$ for all $A \in \Sigma$

(ii) There is a bimeasure $\nu$ on $\Omega=\widetilde{\Omega} \times \widetilde{\Omega}$ having the following properties:

(a) $\tilde{\mu}(A) \leqq \nu(A, \widetilde{\Omega})$ for all $A \in \Sigma$,

(b) $\nu(A, B) \leqq \tau(A \times B \cap C A)$ for all $A, B \in \Sigma$,

(c) $\nu(A, B) \geqq 0$ whenever $A, B \in \Sigma$ are disjoint.

Proof. (ii) $\Rightarrow$ (i) is quite trivial.

(i) $\Rightarrow$ (ii): We introduce in $F$ an order structure localized on $\Omega$ by defining for $\omega=\left(\omega_{1}, \omega_{2}\right) \in \widetilde{\Omega} \times \widetilde{\Omega}$

$$
x \leqq_{\omega} y \Longleftrightarrow x\left(\omega_{1}\right) \leqq y\left(\omega_{1}\right) \text { and } x\left(\omega_{2}\right) \geqq y\left(\omega_{2}\right) .
$$

Then the map $x \rightarrow P(x) \doteqdot \widehat{x}$ is $\Omega$-monotone. Now, consider the linear function $\mu: F \rightarrow \boldsymbol{R}$ given by

$$
\mu(x)=\int_{\tilde{\Omega}} x d \tilde{\mu} .
$$

According to $(*) \Rightarrow(* *)$ the inequality (i) is equivalent to:

$$
\mu(x) \leqq \int_{\Omega} P(x) d \tau \text { for all } x \in F
$$

From our disintegration theorem we then obtain a $\Omega$-monotone linear map $T: F \rightarrow L_{*}^{1}(\tau)$ such that

$$
\int_{\tilde{\Omega}} x d \tilde{\mu} \leqq \int_{\Omega} T(x) d \tau
$$




$$
T(x) \leqq \hat{x}
$$

for all $x \in F$. We define

$$
\nu(A, B)=\int_{\tilde{\Omega} \times B} T\left(1_{A}\right) d \tau \text { for } A, B \in \Sigma,
$$

then $\nu$ has the required properties. The assertion (a) is a consequence of (13) and (b) comes directly out of (14). The $\Omega$-monotony implies (c). All what remains to prove is the $\sigma$-additivity of $\nu$ in the first variable. Take an arbitrary sequence $A_{n} \downarrow \varnothing, A_{n} \in \Sigma$. Then (b) and the positivity of $\tau$ give $\nu\left(A_{n}, \widetilde{\Omega}\right) \leqq \tau\left(A_{n} \times \widetilde{\Omega}\right)$. Hence

$$
\lim _{n \rightarrow \infty} \nu\left(A_{n}, \widetilde{\Omega}\right)=0 \text {. }
$$

If $B_{n}$ is such that $B_{n} \cap A_{n}=\varnothing$ then we get from (c) and (b) that $0 \leqq \nu\left(A_{n}, B_{n}\right) \leqq \tau\left(A_{n} \times \widetilde{\Omega}\right)$. Hence

$$
\lim _{n \rightarrow \infty} \nu\left(A_{n}, B_{n}\right)=0 \text {. }
$$

Now, using the additivity of $\nu$ in both variables one can express the sequence $\nu\left(\widetilde{A}_{n}, \widetilde{B}\right)\left(\widetilde{A}_{n} \downarrow \varnothing, \widetilde{A}_{n}, \widetilde{B} \in \Sigma\right)$ in terms of sequences like (15) and (16). This gives the $\sigma$-additivity in the first variable.

Specializing the Flow Theorem to the case of finite discrete sets $\widetilde{\Omega}$ one immediately obtains Gale's theorem $(|4|,|| 11 \mid$ or $\mid 1$, page 38 (). It is well known that this theorem is closely related to the Ford-Fulkerson theorem. But whereas the Ford-Fulkerson theorem for infinite networks can be obtained from the finite case via Tychonoff's theorem (see $|5|$ ) the situation is slightly more complicated in case of Gale's theorem (although not too different in principle).

\section{REFERENCES}

1. L. R. Ford and D. R. Fulkerson, Flows in networks, Princeton, 1962.

2. B. Fuchssteiner, Decomposition theorems, Manuscripta Mathematica, 22 (1977), 151-164.

3. B. Fuchssteiner and F. D. Maitland Wright, Representing isotone operators on cones, Quart, J. Math. Oxford. 28 (1977), 155-162.

4. D. Gale, $A$ theorem on flows in networks, Pacific J. Math., 7 (1957), 1073-1082.

5. G. Hansel and J. P. Troallic, Measures marginales et theoreme de Ford-Fulkerson, Z. Wahrscheinlichkitstheorie 43 (1978), 245-251.

6. J. Horowitz, Une remarque sur les bimesures, in: Seminaire de Probabilite XI, 59-64, Lecture Notes in Mathematics, 581 (1977).

7. A. and C. Ionescu Tulcea, Topics in the Theory of Lifting, Berlin-Heidelberg-New York, 1969.

8. J. F. C. Kingman, Completely random measures, Pacific J. Math., 21 (1967), 59-79.

9. H. König, Sublineare Funktionale, Arch. Math., 23 (1972), 500-508. 
10. M. Neumann, On the Strassen disintegration theorem, Arch. Math., 29 (1977), 413-420.

11. H. J. Ryser, Combinatorial properties of matrices of zeros and ones, Canad. J. Math., 9 (1957), 371-377.

12. V. Strassen, The existence of probability measures with given marginals, Ann. Math. Statist., 36 (1965), 423-439.

13. M. Valadier, Sur le théorème de Strassen, Comptes R. Acad. Sci. Paris A, 278 (1974), 1021-1024.

14. M. Wolff, Eine Bemerkung zum Desintegrationssatz von Strassen, Arch. Math., 28 98-101.

Received October 12, 1979 and in revised form June 4, 1980.

California Institute of Technology

Pasadena, CA 91125, USA

AND

Gesamthochschule

D. 479 Paderborn 



\section{PACIFIC JOURNAL OF MATHEMATICS}

\section{EDITORS}

DONALD BABBITT (Managing Editor)

University of California

Los Angeles, CA 90024

Hugo RossI

University of Utah

Salt Lake City, UT 84112

C. C. MOORE and ANDREW OGG

University of California

Berkeley, CA 94720
J. DugundjI

Department of Mathematics

University of Southern California

Los Angeles, CA 90007

R. FINN and J. MILGRAM

Stanford University

Stanford, CA 94305

\section{ASSOCIATE EDITORS}
R. ARENS
E. F. BECKENBACH
B. H. NeUmanN
F. WOLF
K. YosHIDA

\section{SUPPORTING INSTITUTIONS}

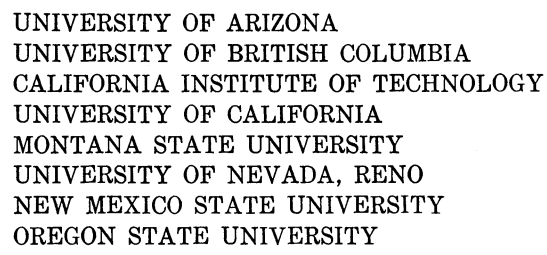

UNIVERSITY OF ARIZONA

UNIVERSITY OF BRITISH COLUMBIA CALIFORNIA INSTITUTE OF TECHNOLOGY

UNIVERSITY OF CALIFORNIA

MONTANA STATE UNIVERSITY

UNIVERSITY OF NEVADA, RENO

NEW MEXICO STATE UNIVERSITY OREGON STATE UNIVERSITY

\author{
UNIVERSITY OF OREGON \\ UNIVERSITY OF SOUTHERN CALIFORNIA \\ STANFORD UNIVERSITY \\ UNIVERSITY OF HAWAII \\ UNIVERSITY OF TOKYO \\ UNIVERSITY OF UTAH \\ WASHINGTON STATE UNIVERSITY \\ UNIVERSITY OF WASHINGTON
}

The Supporting Institutions listed above contribute to the cost of publication of this Journal, but they are not owners or publishers and have no responsibility for its content or policies.

Mathematical papers intended for publication in the Pacific Journal of Mathematics should be in typed form or offset-reproduced, (not dittoed), double spaced with large margins. Please do not use built up fractions in the text of the manuscript. However, you may use them in the displayed equations. Underline Greek letters in red, German in green, and script in blue. The first paragraph or two must be capable of being used separately as a synopsis of the entire paper. Please propose a heading for the odd numbered pages of less than 35 characters. Manuscripts, in triplicate, may be sent to any one of the editors. Please classify according to the scheme of Math. Reviews, Index to Vol. 39. Supply name and address of author to whom proofs should be sent. All other communications should be addressed to the managing editor, or Elaine Barth, University of California, Los Angeles, California, 90024.

50 reprints to each author are provided free for each article, only if page charges have been substantially paid. Additional copies may be obtained at cost in multiples of 50 .

The Pacific Journal of Mathematics is issued monthly as of January 1966. Regular subscription rate: $\$ 102.00$ a year (6 Vols., 12 issues). Special rate: $\$ 51.00$ a year to individual members of supporting institutions.

Subscriptions, orders for numbers issued in the last three calendar years, and changes of address shoud be sent to Pacific Journal of Mathematics, P.O. Box 969, Carmel Valley, CA 93924, U.S.A. Old back numbers obtainable from Kraus Per!odicals Co., Route 100, Millwood, NY 10546.

\section{PUBLISHED BY PACIFIC JOURNAL OF MATHEMATICS, A NON-PROFIT CORPORATION}

Printed at Kokusai Bunken Insatsusha (International Academic Printing Co., Ltd.). 8-8, 3-chome, Takadanobaba, Shinjuku-ku, Tokyo 160, Japan.

Copyright (C) 1981 by Pacific Jounal of Mathematics Manufactured and first issued in Japan 


\section{Pacific Journal of Mathematics}

Vol. 94, No. $2 \quad$ June, 1981

Thomas E. Armstrong and William David Sudderth, Nearly strategic

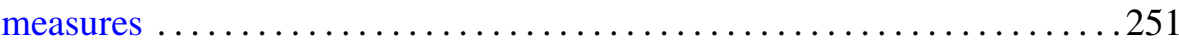

John J. Buoni, Artatrana Dash and Bhushan L. Wadhwa, Joint Browder

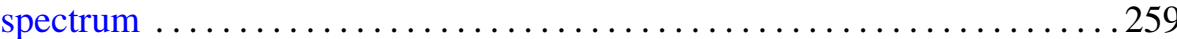

Jack Paul Diamond, Hypergeometric series with a $p$-adic variable . .......265

Raymond Frank Dickman, Jack Ray Porter and Leonard Rubin,

Completely regular absolutes and projective objects ............ 277

James Kenneth Finch, On the local spectrum and the adjoint ........... 297

Benno Fuchssteiner, An abstract disintegration theorem ............ 303

Leon Gerber, The volume cut off a simplex by a half-space $\ldots \ldots \ldots \ldots 311$

Irving Leonard Glicksberg, An application of Wermer's subharmonicity

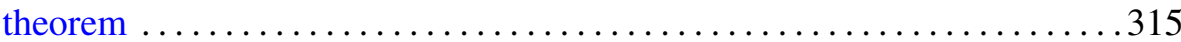

William Goldman, Two examples of affine manifolds ............... 327

Yukio Hirashita, On the Weierstrass points on open Riemann surfaces .....331

Darrell Conley Kent, A note on regular Cauchy spaces ............. 333

Abel Klein and Lawrence J. Landau, Periodic Gaussian

Osterwalder-Schrader positive processes and the two-sided Markov

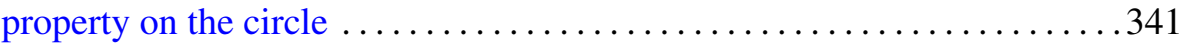

Brenda MacGibbon, $\mathscr{K}$-Borelian embeddings and images of Hausdorff

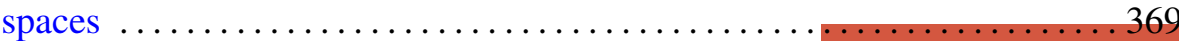

John R. Myers, Homology 3-spheres which admit no PL involutions . . . . . 379

Boon-Hua Ong, Invariant subspace lattices for a class of operators . . . . . 385

Chull Park, Representations of Gaussian processes by Wiener processes . . . 407

Lesley Millman Sibner and Robert Jules Sibner, A sub-elliptic estimate

for a class of invariantly defined elliptic systems $\ldots \ldots \ldots \ldots \ldots \ldots .417$

Justin R. Smith, Complements of codimension-two submanifolds. III.

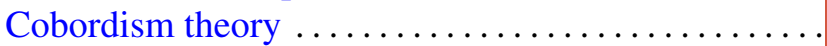

William Albert Roderick Weiss, Small Dowker spaces

David J. Winter, Cartan subalgebras of a Lie algebra and its ideals. II ... 